\title{
Comentário ao livro Dados de Euclides feito pelo filósofo Marino ${ }^{1}$
}

\author{
Tradução e notas de $\mathrm{e}^{2}$ : \\ Húdson Canuto, \\ Instituto Federal de Alagoas (IFAL) \\ canutohudson@gmail.com \\ Juliana Cecci Silva, \\ Universidade Tiradentes \\ julianacecci@yahoo.com.br \\ William de Siqueira Piauí \\ Federal de Sergipe (DFL - UFS) \\ piauiusp@gmail.com
} Departamento de Filosofia e Letras da Universidade

DOI 10.1515/kjps-2016-0010

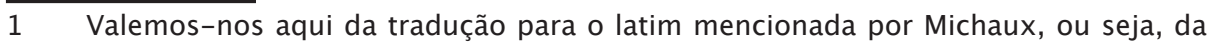
obra "Euclides, Data, aos cuidados de H. Menge e I. L. Heiberg, de 1896, Leipzig: Ed. Teubener"; obra bilíngue (grego-latim) que corresponde ao VI volume da Opera Omnia de Euclides; é a esta edição que se referem os algarismos "234.1" e "256.25", por exemplo, do texto em grego que aparece ao final da presente tradução, isto é, página 234 (início do texto), linha 1 ou página 256 (final do texto), linha 25. Também consultamos a tradução latina de Claude Hardy de 1625 (que certamente foi a lida por Leibniz), obra que também é bilingue. Como não podia ser diferente, a nossa tradução assumiu como referência o trabalho do já mencionado Maurice Michaux, o Le commentaire de Marinus aux Data d'Euclide, de 1947. Segundo o próprio Michaux, Marino teria nascido por volta de 440 d.C em Flávia Neápolis, antiga Sichem, na Palestina; ele substituirá Proclo (410-485) à frente da Academia de Atenas a partir de 484, depois de uma disputa acirrada com Isidoro de Alexandria (ou de Gaza); não se sabe exatamente quando morreu, de qualquer modo, outros historiadores mencionam seu nascimento e morte em mais ou menos 450-500 estimativa que poderíamos estender também para Isidoro.

2 Húdson Canuto é Professor do Instituto Federal de Alagoas (IFAL), mestrando pelo Programa de Pós-Graduação em Filosofia na Universidade Federal de Sergipe (DFL-UFS). Juliana Cecci Silva é Professora da Universidade Tiradentes, tradutora e mestra pelo Programa de Pós-Graduação em Estudos da Tradução na Universidade de Brasilia (Postrad - UnB), e membra do grupo de pesquisa Escritura: Linguagem e Pensamento. William de Siqueira Piauí é doutor em Filosofia pela Universidade de São Paulo (FFLCH - USP), licenciado em matemática pelo IME-USP/Unit e professor adjunto do Departamento de Filosofia e Letras da Universidade Federal de Sergipe (DFL - UFS). 
[234.1] É preciso, em primeiro lugar [1.0], estabelecer o que é o dado

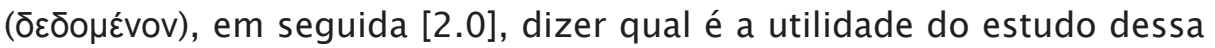
questão e, em terceiro lugar [3.0], a qual ciência ele se associa.

[1.1] O dado é definido de maneiras variadas, [234.5] uma para os antigos outra para os contemporâneos; daí a razão que a sua verdadeira explicação seja difícil de ser fornecida. Alguns nem mesmo deram uma definição dele, mas esforçaram-se em descobrir nele algo particular; outros, combinando o que disseram os primeiros, tentaram defini-lo [234.10]; e mesmo estes não estão em perfeita harmonia.

Todavia, todos parecem coincidir quanto à suposição de que o dado é, com efeito, algo compreendido (ката入птто̀v). Pois os mais limitados deles também tentaram descrever o dado a partir de alguma diferença;

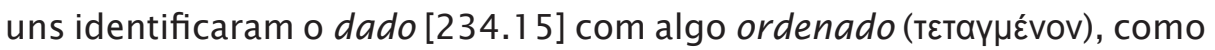

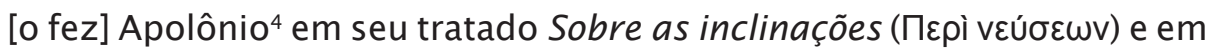

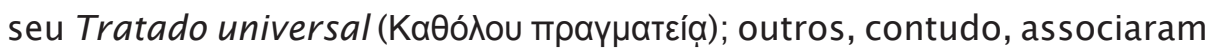
dado com o que seria conhecido (үvúpırov), como [o fez] Diodoro5: "Com efeito, é por essa razão que se diz que os raios e os ângulos são dados e, em geral, tudo aquilo que alcança algum conhecimento (үvw̃oív), ainda

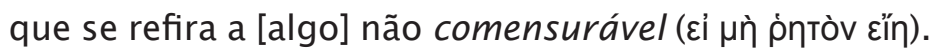

3 Com a numeração "[234.1]", por exemplo, esperamos ajudar o leitor a se localizar com maior precisão e facilidade no texto original grego; com a numeração "[1.0]", "[2.0]" e "[3.0]", quanto às três grandes partes do texto, ou seja, quanto à investigação sobre qual é de fato a natureza do dado, qual a utilidade do estudo de tal questão e a qual ciência ela deve estar associada; além disso, com "[1.1]", "[1.2]", "[1,3] e "[1,4]" quanto às subpartes da primeira grande parte, respectivamente, quanto à suposição que o dado é algo compreendido, quanto às definições que o apresentam a partir de pares de conceitos, sobre o que há de comum e divergente sobre tais conceitos e, por fim, qual é de fato a definição do dado: é o conhecido (gênero) realizável (espécie) [250.25].

4 Marino se refere ao terceiro geômetra mais famoso da Antiguidade depois de Euclides (c. 325-c. 265 a.C.) e Arquimedes (287-212 a.C.), ou seja, a Apolônio de Pérga ou Pérgamo (c. 262 -c. 190 a.C.) de quem a obra mais importante foi o Tratado das Cônicas, talvez aqui considerado com seu Tratado Universal; outros seis trabalhos escritos por ele e lembrados por Papus foram os seguintes: Sobre secções proporcionais, Sobre secções espaciais, Sobre secções determinadas, Lugares planos, Sobre as inclinações (mencionado acima) e Tangências. Segundo Eves (2004, p. 200), desta lista somente o primeiro, em sua versão árabe, chegou aos nossos dias.

5 Diodoro de Alexandria, matemático e astrônomo do primeiro século a.C., famoso pupilo de Posidônio de Apameia (135-51 a.C.). Não conseguimos saber quais obras teria escrito e se haveria dentre elas uma com título similar a Sobre os dados. 
Outros, entretanto, acreditaram que seria o próprio [234.20] comensurável (p̀ntòv), como queria Ptolomeu ${ }^{6}$, que chama dado àquilo cuja medida é conhecida (үvẃpırov) [236.1] exatamente ou muito proximamente [do exato].

E outros pensaram que o dado era aquilo que se propõe na hipótese por aquele que a enuncia. Nos Elementos [de Euclides] (таі̃ при́таı

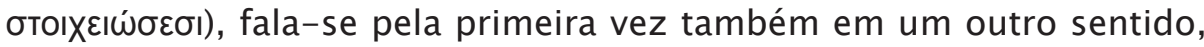
como de uma dada [236.5] reta, como se alguém determinasse e desse o comprimento dessa dada reta.

Todas essas coisas, de fato, tendem a significar uma certa compreensão (кaтó $\lambda \eta \psi i ́ v)$. É por isso que, entre as definições, as mais aceitas são as que melhor expressam o compreendido (катаһппто̀v), como mostraremos em seguida.

[236.10] [1.2] Agora, contudo, expomos as diferentes sentenças daqueles que não caracterizam de modo limitado a natureza do dado como algo único, e que dele dão mais de um tipo de definição ${ }^{7}$. Todavia, podemos enumerar muito facilmente as diferentes sentenças de todos eles.

Com efeito, uns definiram o dado como aquilo que é conjuntamente

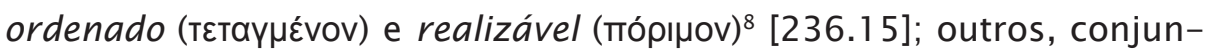

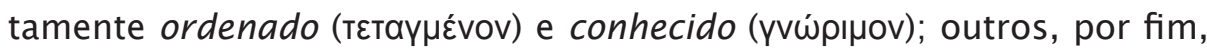
conjuntamente conhecido (үvúpııov) e realizável (mópı $\mu$ ov). Pois, como os precedentes, parecem ter em mente a compreensão (кaт́́ $\lambda \eta \psi \mathrm{IV}$ ) e mes-

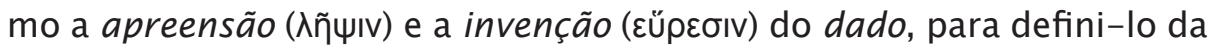
maneira que dissemos.

Também para [236.20] percebermos mais plena e abundantemente e, em meio a todas aquelas, extrair a verdadeira definição do dado em questão, investigaremos primeiramente o significado de cada termo simples e de seu contrário, quero dizer, do desordenado (áтókтоu), do desconhecido

6 Cláudio Ptolomeu (c. 95-c. 165), filósofo antigo que escreveu o "trabalho grego definitivo sobre astronomia" (EVES, 2004, p. 204), ou seja, o famoso Almagesto, e que é mencionado aqui certamente por seus trabalhos em Matemática, disciplina que, como ficará claro principalmente ao final da presente tradução, não estava separada da Física, Astronomia ou Música.

$7 \quad$ Na verdade, Marino se refere a definições fornecidas aos pares, como ficará claro no parágrafo imediatamente seguinte.

8 Seguimos aqui a sugestão de tradução feita por Maurice Michaux (1947), p. 26. 


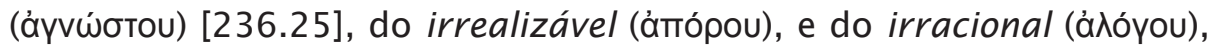

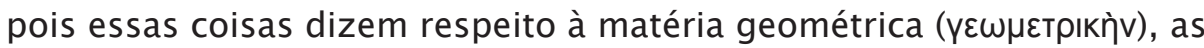

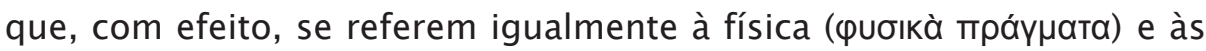

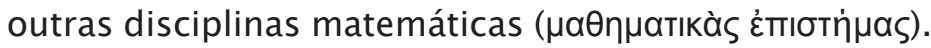

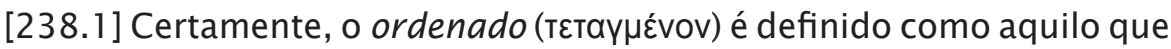
permanece sempre idêntico a si mesmo a partir do que se diz que está or-

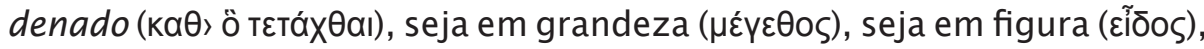
seja quanto ao que quer que for diferente ou de outro modo se defina; o que não pode ser de outra maneira, mas continua imutável [238.5] em um lugar bem delimitado; como, por exemplo, a reta ( $\varepsilon \dot{\theta} \theta \tilde{\varepsilon} \alpha)$ traçada por dois

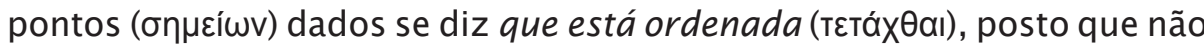
pode ser dito de um outro modo e tem uma posição fixa. O desordenado

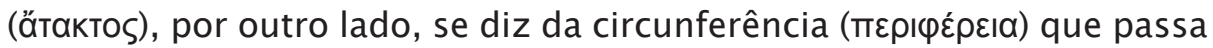
por dois [pontos], de fato, ela pode ser traçada de variadas maneiras e

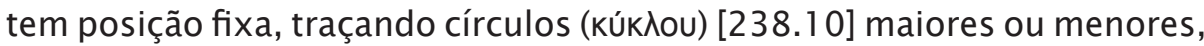
ao infinito (ämeıpov), que passem por esses dois pontos. Ao contrário,

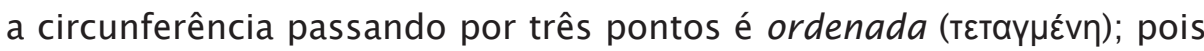

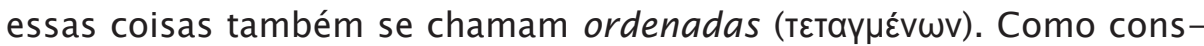

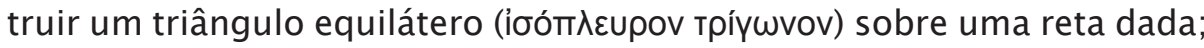
visto que pode ser construído de dois modos, mas, de cada [238.15]

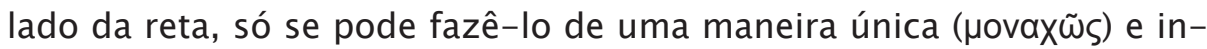

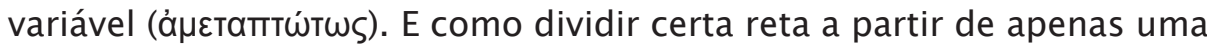

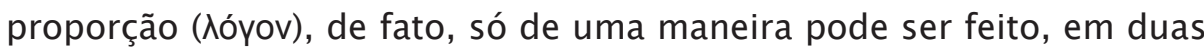
iguais. Desordenadas (ä́ткта) são as coisas opostas àquilo que precede;

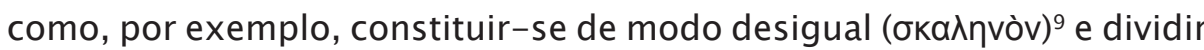
a reta de uma maneira [238.20] indefinida (áopíotws). Assim, é preciso associar à definição o aspecto sob o qual a coisa se diz ordenada (каӨ) ö

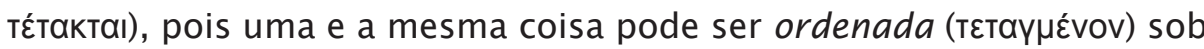
um aspecto, mas desordenada (ä́актоv) sob um outro; por exemplo, o

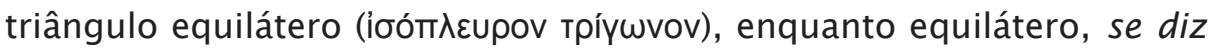
ordenado (тв́тактаı), mas em grandeza ele é não determinado (oủX üрıбтаı) inteiramente.

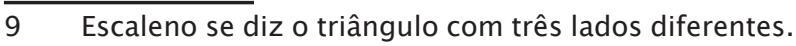


[238.25] O conhecido (үvẃpıpov) é aquilo que é reconhecido

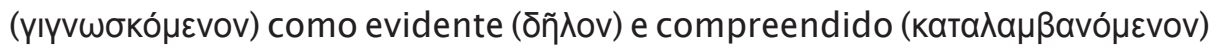
por nós. Do mesmo modo, o desconhecido (ấvvwotov) é aquilo que não é reconhecido nem compreendido por nós. Por exemplo, para dizer que a extensão da estrada é conhecida (үvúpınov) é preciso que se tenha compreendido quantos [240.1] estádios ${ }^{10}$ ela tem; e, do mesmo modo, o fato de que a soma dos ângulos internos de um triângulo é igual a dois retos

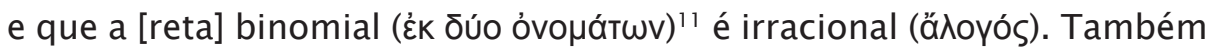
são ditas conhecidas (үvúpııa) coisas tais como: partindo de um ponto exterior [240.5] para duas das partes, existe apenas uma tangente

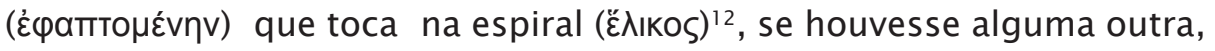
então duas retas compreenderiam certo espaço (xwpíov), o que é impossível (áoúvatov). Entretanto, as que são desconhecidas (ä́vwota) não são as irracionais (ä̉oyó), mas sim aquelas que não são nem conhecidas

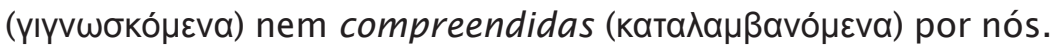

O realizável (mópıнov) diz-se daquilo que é possível (סuvatoí) fazer-

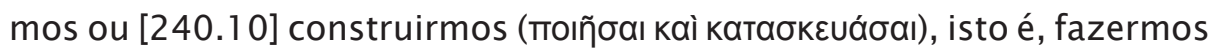

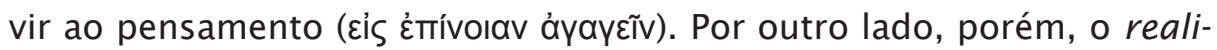
zável (mópınov) se diz daquilo que se pode realizar por demonstração

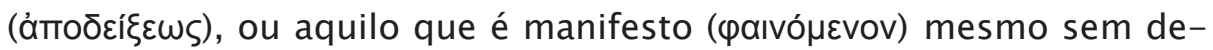
monstração; como, por exemplo, traçar um círculo conhecendo o centro e o raio; compor tanto um triângulo [240.15] equilátero quanto um escale-

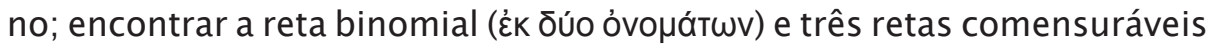

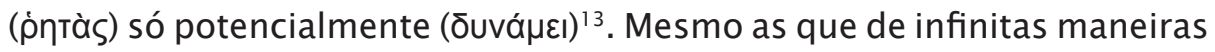

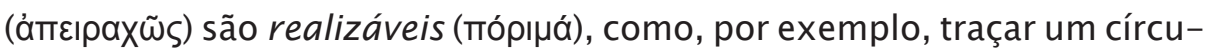
lo que passe por dois pontos. O irrealizável (ämopov) é o que leva ao opos-

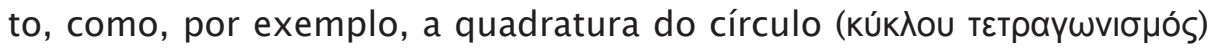

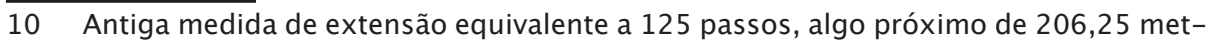
ros.

11 Expressão que aparece especialmente a partir da proposição 36 do livro X dos Elementos de Euclides.

12 Traduzimos o termo grego ह̌ $\lambda$ ıко por "espiral" (que corresponderia ao grego бтвípa, e não ह̌ $\lambda$ Iкоऽ) tendo em vista que, como nos indica Maurice Michaux (cf. op. cit. p. 58),

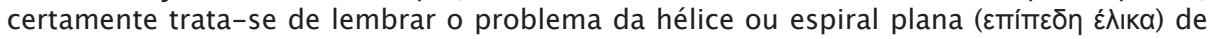
Arquimedes, que escreveu um tratado de título Sobre as espirais.

13 Expressão que segundo Michaux significa das "quais os quadrados são comensuráveis", op. cit. p. 58. 
[240.20] ${ }^{14}$. Pois ainda não está realizado (пópழ̣), ainda que realizável

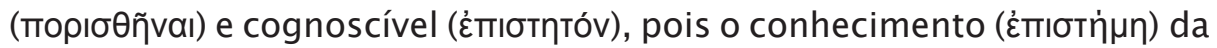
quadratura do círculo ainda não foi alcançado. Mas, nesse momento, nós tratamos daquilo que já está realizado (mópw), daquilo que chamamos de legitimamente realizável (kupíws mópınov). Pois aquilo que ainda não foi realizado (по́ $\omega)$, [240.25] mas eventualmente é realizável (порıбӨñval), é designado particularmente de realizado (порıбтòv íoíws). O irrealizável (ắтороv), como foi chamado, é o contrário do realizável (порі́ w), ou seja, é aquilo sobre o que a investigação não encontrou solução.

O comensurável (ṕntòv) é aquilo do que podemos fornecer a grandeza

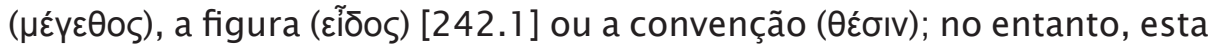
definição é geral demais; propriamente e em si mesmo, o comensurável (ṕntóv) é aquilo de que nós conhecemos a quantidade com relação a uma medida convencionada, como o palmo ou mesmo o dedo.

[242.5] [1.3] Definidos estes termos, a partir de agora será mais fácil examinar o comum e o divergente quanto às noções das quais falamos.

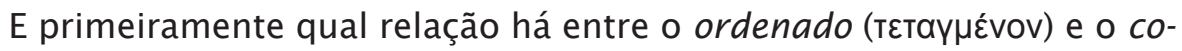
nhecido (үvẃpınov) e os que se opõem a eles. Com efeito, não dizemos que estes termos são convertíveis [242.10] nem com os que são mais amplos que eles; ainda que muitas coisas Ihes sejam comuns, por exemplo, traçar uma reta passando por dois pontos e constituir lados iguais [de um triângulo] a partir de três círculos, entretanto, a quadratura do círculo

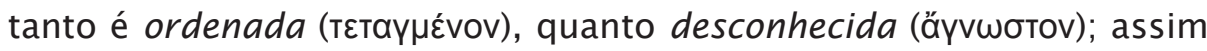
como o fato de existir apenas uma tangente que toca na [242.15] espiral (

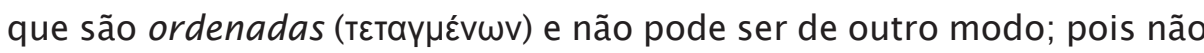

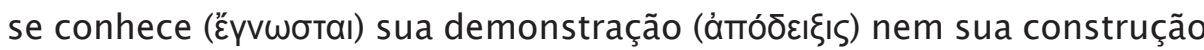

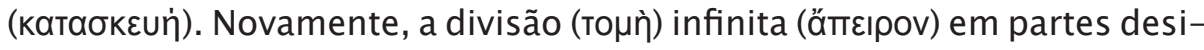

14 Como nos lembra Eves (2004, p. 140): "Provavelmente nenhum outro problema exerceu um fascínio maior ou mais duradouro do que aquele de construir um quadrado de área igual à área de circulo dado. [...] O primeiro grego conhecido cujo nome se liga ao problema é Anaxágoras (c. 499-c. 427 a.C.), mas sua contribuiç̧ão é desconhecida. Hipócrates de Quio, um contemporâneo de Anaxágoras, teve sucesso na quadratura de certas lunas especiais [...]. Alguns anos mais tarde, Hípias de Elis (c. 425 a.C.) inventou uma curva que se tornou conhecida como quadratriz. [...] Pode-se conseguir uma solução elegante do problema da quadratura com a espiral de Arquimedes que, efetivamente, foi utilizada por ele com essa finalidade". 


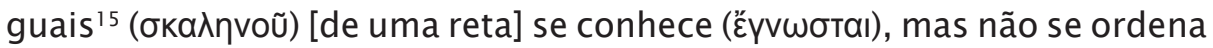

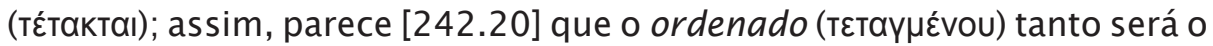
conhecido (үvúpıнov) quanto o desconhecido (äpvwotov), e, inversamente,

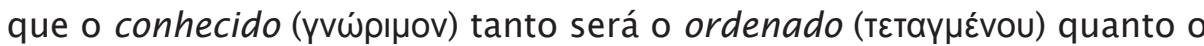
desordenado (ä́тктоv). E esses termos se relacionam assim como o lógico

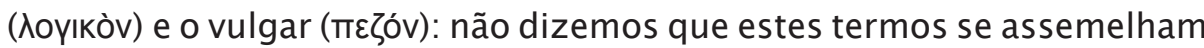
nem mesmo [242.25] com os que são mais amplos que eles ${ }^{16}$.

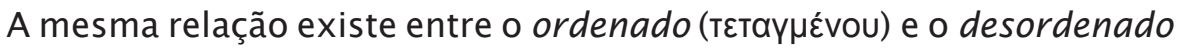
(ä́тактоv) de um lado, e o realizável (по́pıнov) e o irrealizável (ä́тороv) de outro. De fato, a semelhança entre estes termos é a maior possível, mas diferem pelos motivos que [244.1] dissemos. Portanto, a espiral (ع̌ $\left.\lambda_{1} \xi\right)$ é ordenada (те́тактаı), mas ela não estava realizada (порі́ quimedes. Pelos mesmos motivos as que podem ser conhecidas de infi-

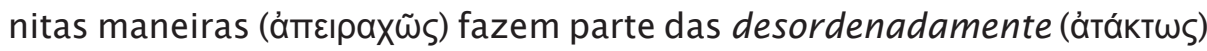
realizáveis (пópıнa), se alguém conhecesse sua constituição e sua construção; de qualquer modo, entretanto, elas não fazem parte [244.5] das

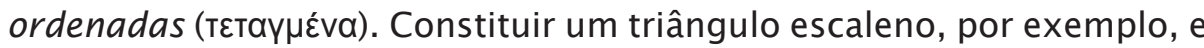
ter trazido ao intelecto (ávayayeĩv tìv ठıóvoıav) a sua realização a partir do equilátero não é nada difícil, ainda que seja desordenado (átóktwv) e de infinitas maneiras (ámeípwv).

E também a relação entre o comensurável (ṕntòv) e o irracional (ä̉oyov)

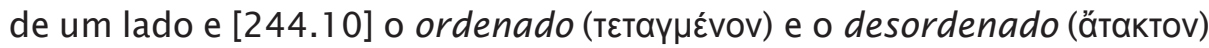
de outro lado; pois, se convêm em muitos termos, pelos mesmos motivos também diferem. De fato, esses termos nem se tornam alternadamente iguais nem um compreende o outro; com efeito, a reta binomial (غ̇k ठúo

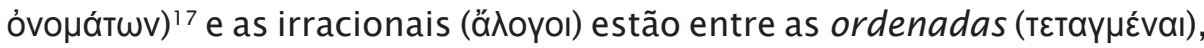

15 Marino parece se referir à seguinte afirmação feita anteriormente: "É como dividir certa reta a partir de apenas uma proporção ( $\lambda$ óyov); de fato, só de uma maneira pode ser feito, em duas iguais. Desordenadas (ä́akта) são as coisas opostas àquilo que precede;

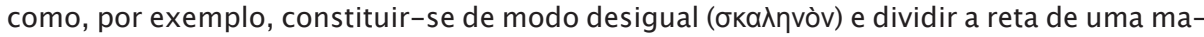

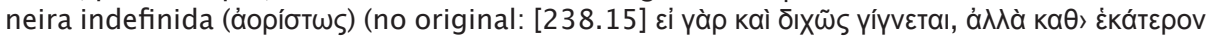

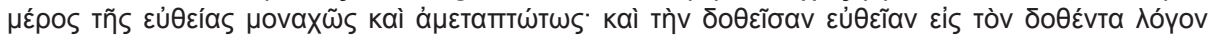

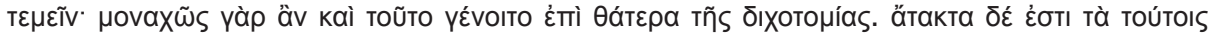

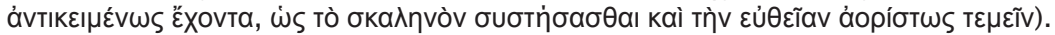

16 Retomada do que disse mais acima: "Com efeito, não dizemos que estes termos são convertíveis nem com os que são mais amplos que eles" (no original: [242.10] oủk ह̌бт ठ̀̀

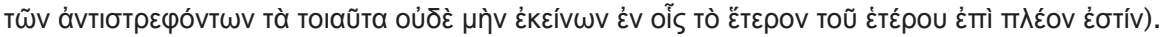

17 Cf. [240.8] e [240.15]. 
[244.15] mas não entre as comensuráveis (p̀ntaí), tal como a relação da

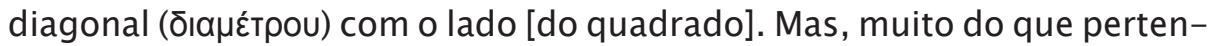
ce ao comensurável (ṕntw̃v) é desordenado (ä́тактá), como o que de muitas e indeterminadas maneiras é conhecido; pois, o triângulo escaleno pode ser medido a partir de uma medida comensurável (ṕnтоũ) convencionada e determinada, ainda que seja [244.20] desordenado (ä́тактоv).

Qualquer um pode emparelhar facilmente as semelhanças entre o conhecido (үvwpínou) e o realizável (тópınov), todavia, é difícil ter compreendido a diferença; com efeito, eles são por natureza muito próximos um do outro e, por conseguinte, parecem ser equivalentes. Mas não é nada disso para quem examiná-los [244.25] com mais diligência, quando alguma diferença será percebida; pois, é um fato aceito e conhecido (үvúpııov), que só existe um ponto em que uma única reta tangente toca à espiral

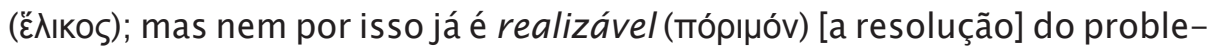

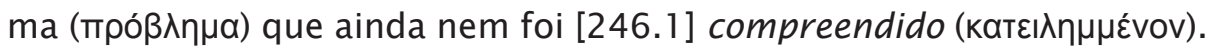
Assim como tudo o que é conhecido (үvẃpııov) nem por isso é realizável

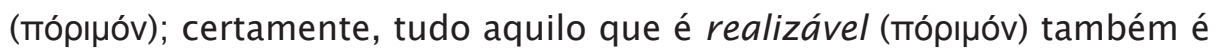
conhecido (үvẃpıнov); assim, pois, o conhecido (үvúpıнov) é mais amplo que o realizável (порі́nоu).

Ademais, o conhecido (үvúpırov) e o comensurável (ṕntòv) [246.5] concordam em alguns pontos, mas não em outros, pelos mesmos motivos que já dissemos. Com efeito, as linhas irracionais (ä入oyoı) mencionadas são conhecidas (үvúpııoı), mas não comensuráveis (p̉ntaí); enquanto todo número é comensurável (p̉ntòs), mas nem todo é conhecido (үvúpııos).

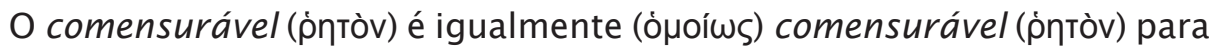
aquelas coisas que têm o mesmo uso (ع̈Өos); e [246.10] um comprimento

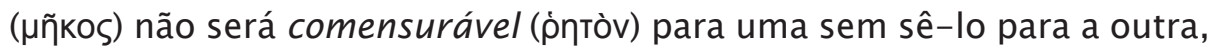
tendo em vista que assumirão (ávoí́ouбı) a mesma medida. E o próprio comprimento se torna (үíyvetaı) conhecido (үvẃpııov) para uma e não para

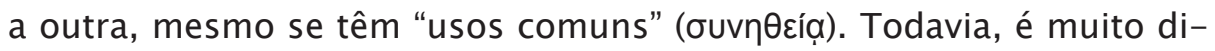
fícil encontrar algo que seja comensurável (p’ntòv), porém desconhecido (äүvwotov). É evidente, pois, que o conhecido (үvẃpıнov) é mais geral do que comensurável (ṕnтoũ) [246.15].

Porém, que o realizável (пópınov) e o irrealizável (ǻmopov) diferem do

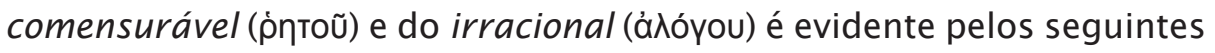
motivos, a saber: é possível (סuvatòv) que alguns dos irracionais (ảóywv) 


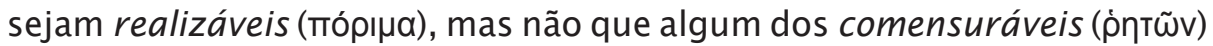
seja irracional (ä入oyov). E a semelhança entre essas noções e [246.20] as outras é perceptível a todos; de tal modo que seguramente umas compreendem as outras, assim como o realizável (mópınov) parece ser mais amplo do que o comensurável (p̀nтoũ).

E podemos examinar a diferença das noções mencionadas também da seguinte maneira, a saber: o comensurável (p̉ntòv) e o irracional (ä̉oyov) são [246.25] assim chamados enquanto associados a uma medida, não enquanto enviados ao nosso conhecimento (үvw̃oıv). De fato, é possível que algo comensurável (p̀ntòv) não nos seja conhecido (үvúpınov); de maneira que é comensurável (p̉ntóv), mas ainda não foi compreendido

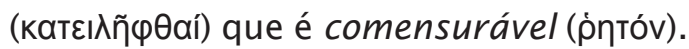

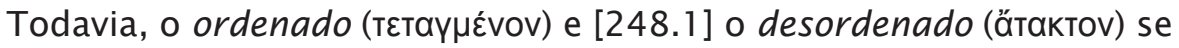
referem ao que em si mesmo e por sua própria natureza é assim considerado, mesmo ainda não sendo compreendido por nós. Seja como for, muitas coisas Arquimedes provou posteriormente que eram ordenadas

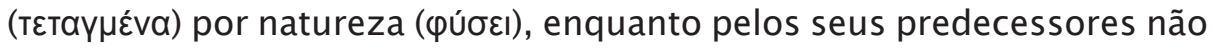

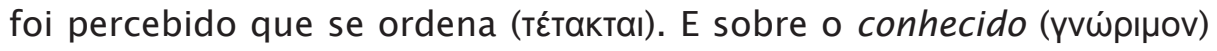
[248.5] e o desconhecido (äyvwotov), falamos no que se refere a nós. Como podem se diferenciar as invenções de uns para os outros; se, de fato, quanto a nós, têm referência tanto à natureza quanto à medida.

[1.4] Definido em quê os termos supracitadas são comuns e diferentes

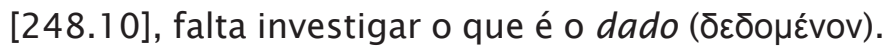

Pois bem, muitos que supuseram ser o dado aquilo que é dado por hipótese por quem a propõe se distanciam da questão. Com efeito, todos os elementos que tratam dos dados não [248.15] são, a propósito dele próprio, compostos por hipótese, como é lícito observar percorrendo os tratados sobre ele ${ }^{18}$. Mas, por isso, abandonamos uma tal concepção

18 Certamente no sentido em que livros como o de Euclides, ou seja, Os elementos,

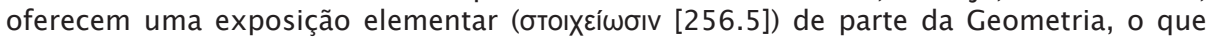
poderia ser feito com respeito à parte referente aos dados. Quanto aos tratados sobre os dados, além do de Euclides, Marino deve estar se referindo também aos tratados Sobre os dados que teriam sido escritos por Arquimedes, o qual se perdeu, e ao de Papus. Vale lembrar que muito eram os tratados que de algum modo consideravam $o$ dado sem tê-lo como assunto principal, ao que parecem se referir, por exemplo, as menções a Apolônio, Diodoro e Ptolomeu em [234.15]. 


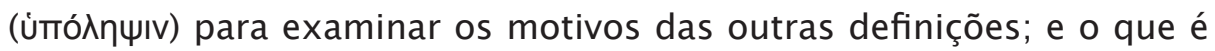
do dado por hipótese, se considera em conformidade com os princípios (ápxaĩs) [248.20].

Além disso, aqueles que de fato delimitaram as definições a uma só palavra, caracterizaram-nas a partir dos termos mencionados, como foi dito no começo; e todos parecem ter tido um pensamento comum a respeito do dado; com efeito, eles o conceberam como algo compreendido

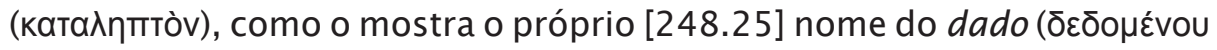
óvoua); e entre eles principalmente os que o descreveram como o dado

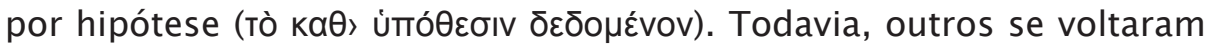

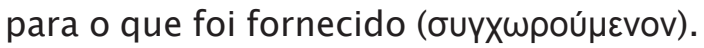

A partir de agora, faremos uso do que foi mencionado como regra (Kavóvı) e critério (крıтnрíw) para poder [250.1] encontrar a definição per-

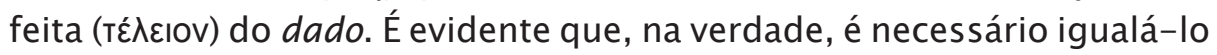
e fazê-lo voltar ao que é definido (ópıotóv); e ainda, de fato, isso é o necessário para as definições serem estabelecidas corretamente. Mas, é do tipo [250.5] proposto, com respeito às mencionadas definições mais simples ${ }^{19}$, aquela que identifica o dado com o realizável (пópınov), e, com respeito às definições mais complexas, aquela que o identifica com o que é ao mesmo tempo conhecido (үvúpııov) e realizável (пópıнov). Todas as

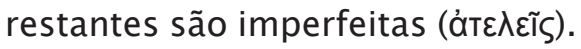

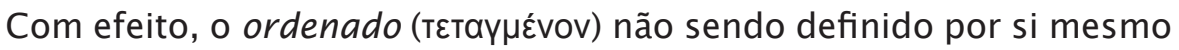
com relação à delimitação do dado, [250.10] por um lado nem todo e por

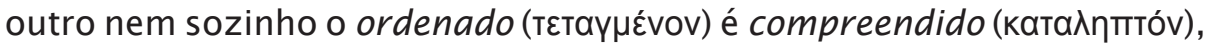
mas também são aquelas desordenadas (áTáktwv), assim como foi mostrado.

Não é suficiente quanto ao conhecido (үvúpınov) mesmo sendo separado, isto é, nem todo o conhecido (үvẃpııov) é compreendido (ката入птто́v), ainda que sozinho o seja; pois que o desconhecido (ăyvwotov) não poderia ser compreendido (ката入ппто́v).

Seguramente [250.15] aquele que expressa o comensurável (ṕntòv) em uma só definição não será perfeito, pois nem este sozinho é compreen-

19 Talvez na categoria das definições de um só conceito, vide pouco acima o texto [248.20]. 
dido (ката入птто́v), posto que também aqueles estão entre os irracionais

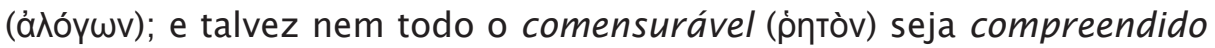
(ката入ппто́v), assim como foi definido anteriormente.

Resta agora, por fim, entre as que transmitem em apenas uma palavra a do realizável (mópıнov), a que certamente parece expressar melhor

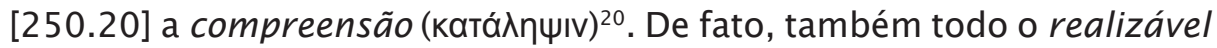

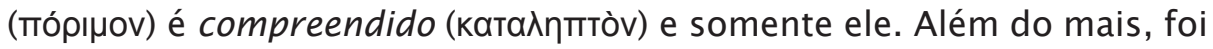
esta definição que Euclides utilizou ao descrever todas aquelas formas do dado.

Dentre as definições mais compostas, a única perfeita é aquela que delimita o dado com aquilo que é ao mesmo tempo conhecido (үvẃpı e realizável (тópınov), [250.25] associando o análogo tanto do conheci-

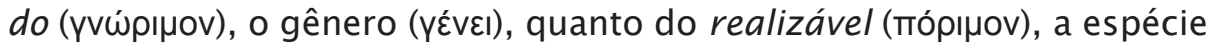
$(\delta ı \alpha \varphi \circ \rho \tilde{\alpha})^{21}$.

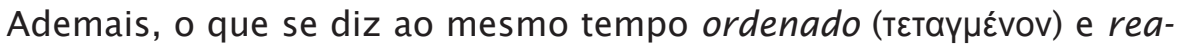
lizável (тópırov) está imperfeito, tendo em vista que sozinhos eles não

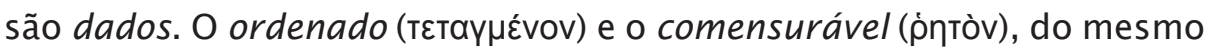
modo, encerra insuficientemente [252.1] o dado; e o ao mesmo tempo

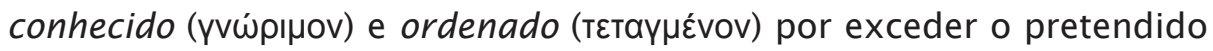
não estará bem; tendo em vista que nem todos eles são dados.

Somente os restantes, por fim, parecem ter alcançado o conhecimento (żvoías) do dado, os que o expressam como o que é ao mesmo tempo

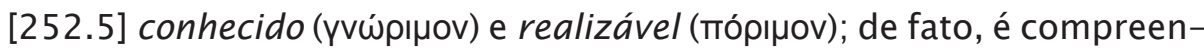
dido (ката入птто̀v) no todo e sozinho; e essas duas [características] devem se encontrar em quaisquer definições cientificamente dadas. E próximo disto estão os que as compõem da seguinte maneira: o dado é aquilo que

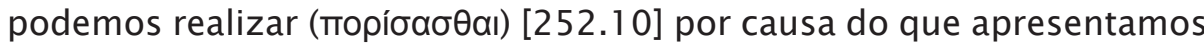

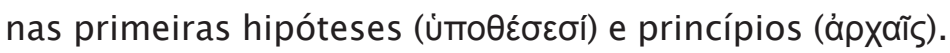

E entre os que mencionamos também pode estar Euclides, por ter usa-

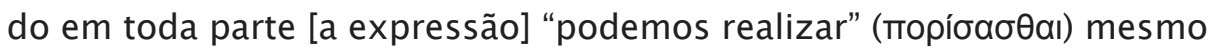
quando omite o conhecido (үvẃpııov), considerando-o como se seguin-

20 Evidentemente, trata-se das definições de um só conceito. Finalmente, Marino está de volta ao que havia suposto ao final de [1.1], cf. [234.10].

21 Tal qual a seguinte definição: o homem (como o dado) é um animal (gênero, como $o$ conhecido) racional (espécie, como o realizável). Daí que: o dado é o conhecido realizável. 
do ao realizável (порі́ razão por não ter delimitado primeiramente [252.15] o dado em geral

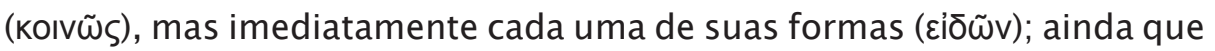

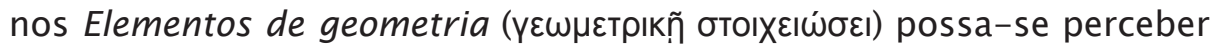
que ele delimitou a linha simplesmente antes das formas das linhas ${ }^{22}$, e do mesmo modo [fez com] as outras.

[2.0] Assim, tendo, pois, examinado por um lado o mais geral quanto ao dado e, [252.20] da mesma forma, por outro trazido à tona tal assunto, agora podemos fornecer a utilidade com relação a tratar disto. $E$, pois, ele faz parte dos que têm para com um outro a prerrogativa; seu conhecimento é dos mais necessários para o que se chama tesouro

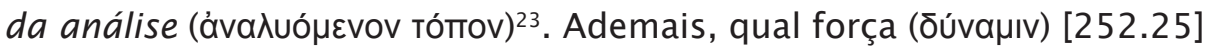

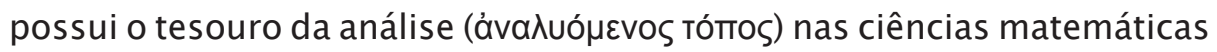

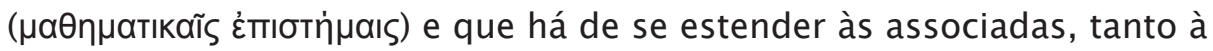
ótica (ómтıñ̃) quanto à canônica (кavovıкñs), nós o consideramos alhures;

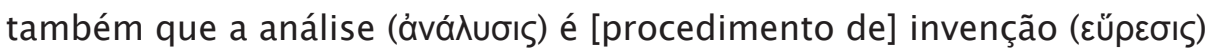

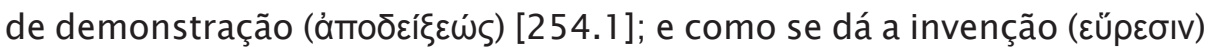

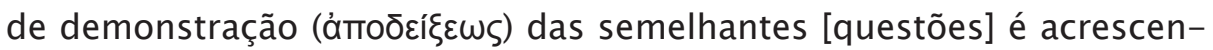
tado por nós; bem como que é preferível adquirir a faculdade de analisar

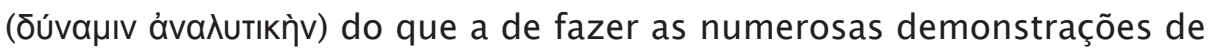
parte delas.

22 Cf. Os elementos livro I, definições 2-4.

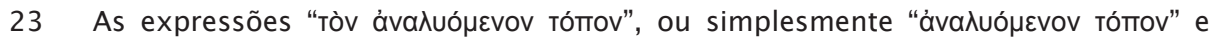

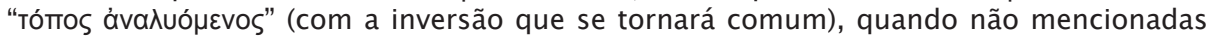
no próprio grego, foram muitas vezes traduzidas pelas latinas resolutus locus, pertinentia loco ou corpus analitico, dentre outras; entretanto, ficamos com a sugestão de T. Heath (1981, p. 421) repetida por Irineu Bicudo em sua introdução ao Os elementos (EUCLIDES, 2009 , p. 49), ou seja, com тómoৎ fazendo referência ao treasury (bem precioso), ao depósito, ao estoque, ao Tesouro da Análise. E a menção posterior a Papus de Alexandria (c. 290-c. 350 d.C.) deixa pouca margem de erro para esta interpretação, já que o próprio havia explicado o que ela queria dizer em sua Coleção matemática; daí termos optado pela expressão "tesouro da análise". Gostaríamos de mencionar o fato que as aparições de tal expressão em textos de matemática em muitos casos permitem restabelecer uma linha histórica com respeito não só à Análise, mas também à Topologia, a qual teria origem na matemática da Antiguidade (principalmente alexandrina), passaria pela dos hindus e árabes, para no Renascimento chegar a Europa e depois ser associada por Leibniz, no texto homônimo, à expressão latina Analysis situs, a qual será lembrada por Poincaré ao falar da parte da Topologia que se refere principalmente à hipergeometria. 
[254.5] [3.0] Assim, a teoria do Dado sendo, pois, útil para todas aquelas disciplinas, e dado que acrescenta grande [utilidade] à análise, o correto seria dizer que se estabelece não associada a certa ciência daquelas,

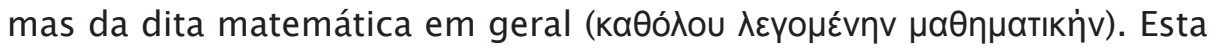
que compreende [254.10] as quantidades ( $\pi \lambda \dot{\eta} \theta \eta)$, as grandezas ( $\mu \varepsilon ү \varepsilon \dot{\theta} \eta \eta)$,

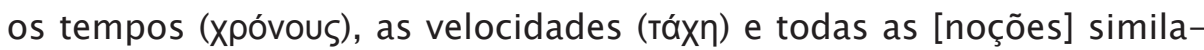
res, bem como que também trata das relações (入óyous) e proporções

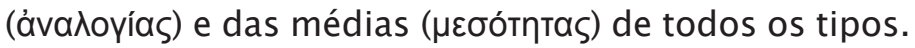

Assim pois, para a própria compreensão científica utilíssima dos dados tendo sido [254.15] confeccionado o livro de Euclides Sobre os dados

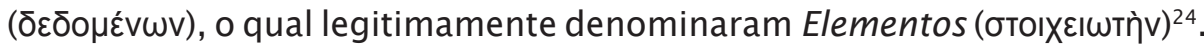
Com efeito, para quase toda a ciência matemática ele propôs os elemen-

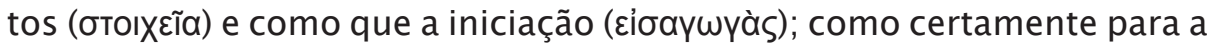
geometria em todos seus treze livros e para a astronomia em Os fenôme-

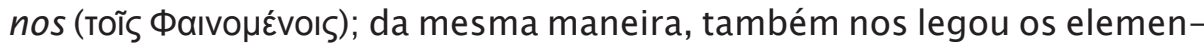

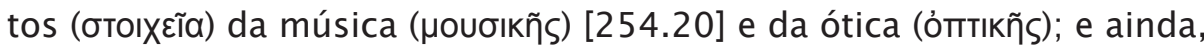
também em todo o tratado Sobre os dados, elaborou o livro estabelecendo

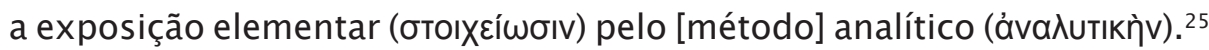

Porém, sendo geômetra, diferenciando as grandezas das generalidades relativas ao dado as adaptou particularmente; tendo produzido do modo como também [tratou] da generalidade das relações e a das grandezas em particular [254.25], o plano das mesmas tendo sido tratado no quinto livro [dos Elementos].

De modo geral, por conseguinte, certamente dissemos o que é o dado e [256.1] a partir de qual ciência ele é conduzido, bem como que é de grandíssima utilidade uma teoria sobre ele. Todavia, acrescentamos a isso as coisas que foram ditas e a delimitação da ciência que a ele concerne. Por fim, ela será igualmente evidente a partir das coisas que foram ditas, uma compreensão (кат́́ $\lambda \eta \psi ı$ ) de [256.5] toda espécie de dados e

24 Em pleno acordo com o que nos atesta Heath (1982, p. 421), o assunto dos livros I a VI dos Elementos é o "dado", o que é confirmado por Eves (2004, p. 180).

25 Além do Os elementos, do Sobre os dados, do Fenômenos, Óptica e Elementos de música, o criador da Escola de Alexandria (o Museu), Euclides, também teria escrito os seguintes trabalhos: Divisão das figuras, Pseudária (ou Das falácias), Porismas, Lugares em uma superfície e Cônicas. Existe uma discussão bastante elementar sobre quase todos eles feita na introdução de Irineu Bicudo ao Os elementos, cf. especialmente as pp. 45-63. 
daquilo que a ele se associa. Contudo, em particular frente ao livro, dize-

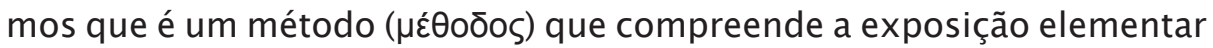

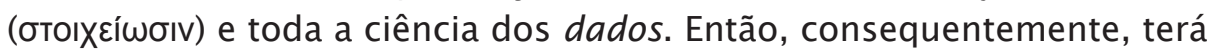
utilidade inclusive para as outras que, com respeito [256.10] à prerrogativa, se relacionam com o dado.

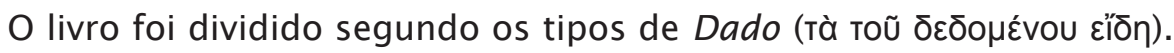
A sua primeira seção compreende os dados de acordo com a razão (tò

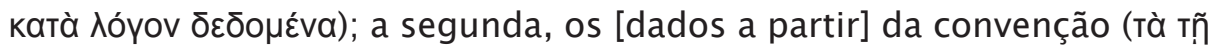

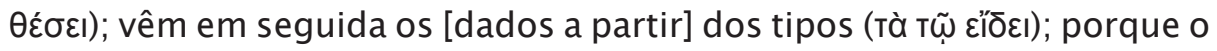

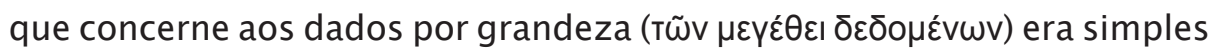
[256.15] foi espalhado em muitas das partes e sobretudo com respeito

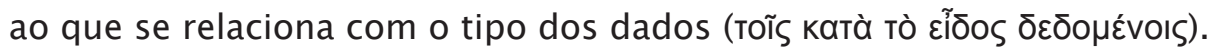

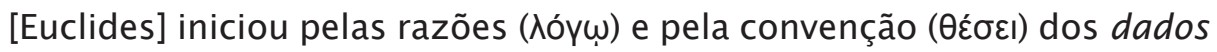

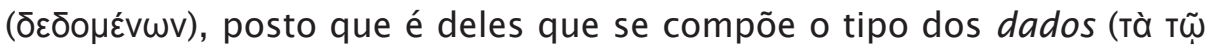

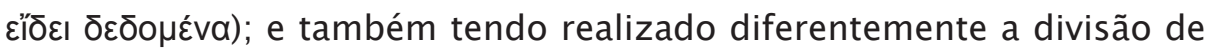

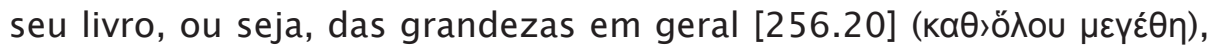

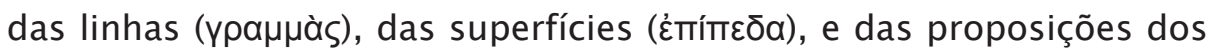

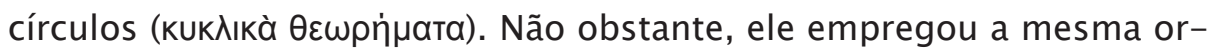

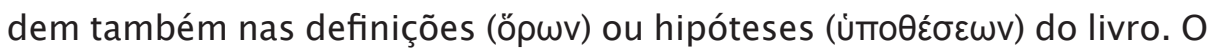

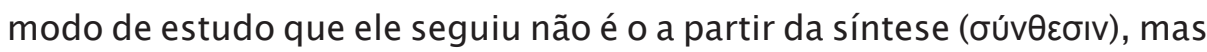
o a partir da análise (ávóluoıv) ${ }^{26}$, como Papus $^{27}$ o [256.25] demonstrou

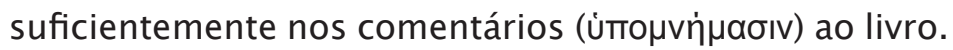

26 De forma bastante abreviada nos explica Irineu Bicudo: "Pappus mostra com exemplos como os Data prestam serviço à análise. Esta começa com uma construção suposta que satisfaça as condições propostas [a ह̌k $\theta \varepsilon \sigma ı \zeta]$. Tais condições, sendo convertidas em elementos dados da figura, envolvem outros que são dados por implicação, e esses, por

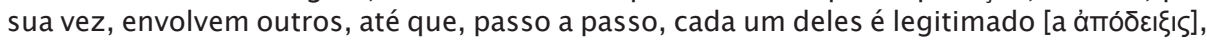
e chega-se a uma construção da qual se obtém uma síntese. [...] Os Data são, de fato, sugestões para as etapas mais usuais na Análise" (EUCLIDES, 2009, p. 51).

27 O famoso geômetra já mencionado, Papus de Alexandria, que deve ter vivido mais ou menos entre 290 e 350 da nossa era, foi o responsável por reascender com "competência e entusiasmo", nas palavras de Eves, o interesse pela geometria quase 600 anos depois da existência do trio Euclides, Arquimedes e Apolônio. Para o que mais nos interessa, Eves (2004, p. 210) comenta: "Papus escreveu comentários sobre os Elementos e Os dados de Euclides e sobre o Almagesto e Planisfério de Ptolomeu, mas quase tudo que sabemos sobre isso é sobre a influência exercida sobre os escritos de comentadores que se seguiram. O trabalho realmente grande de Papus é sua Coleção matemática, uma combinação de guia da geometria da época, acompanhado de comentários, com numerosas proposições originais, aprimoramentos, extensões e notas históricas. Dos oito livros que compunham a obra perderam-se o primeiro e parte do segundo. [...] O livro VII é históricamente im- 


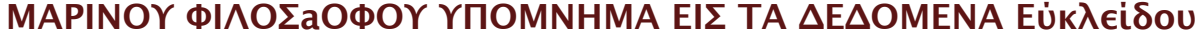

\section{4.[linha] 1}

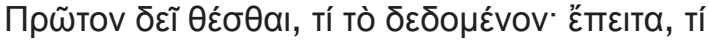

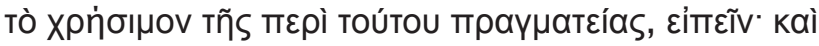

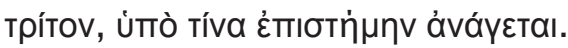

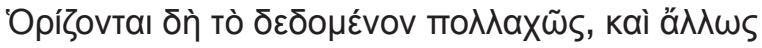

\section{5}

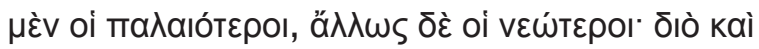

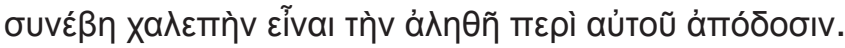

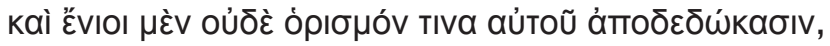

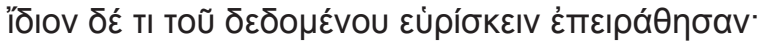

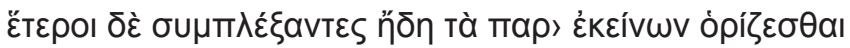

234.10

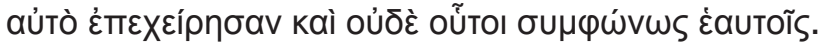

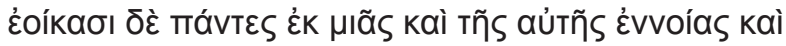

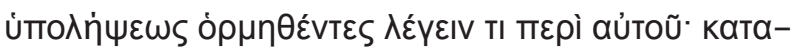

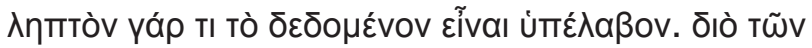

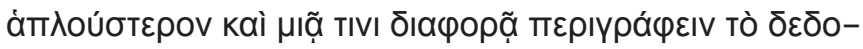

\subsection{5}

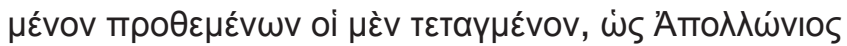

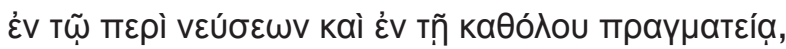

portante, pois dá uma descrição dos trabalhos que constituem O Tesouro da Análise, uma coleção que, à maneira dos Elementos de Euclides, pretende abarcar o material que se considerava essencial como bagagem do matemático profissional. Os doze tratados discutidos são Os dados, Porisma e Lugares de superfície de Euclides; Seções Cônicas e os seis trabalhos de Apolônio [Sobre secções proporcionais, Sobre secções espaciais, Sobre secções determinadas, Lugares planos, Sobre as inclinações e Tangências] (vide nota 4) [...]; Lugares sólidos de Aristeu e Sobre médias de Erastótenes". 


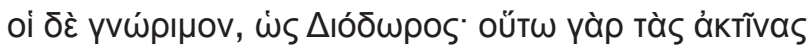

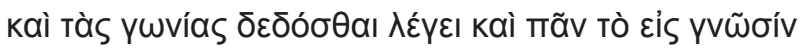

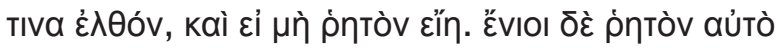

234.20

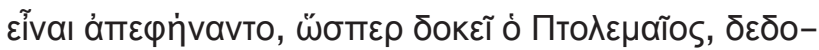

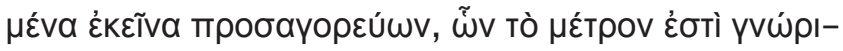

236.1

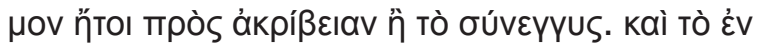

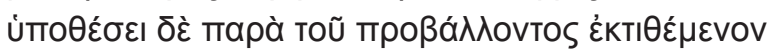

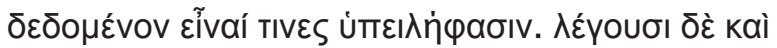

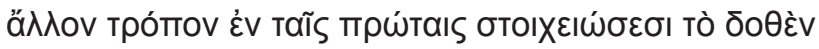
236.5

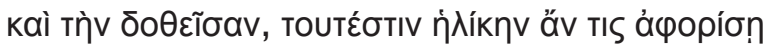

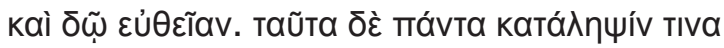

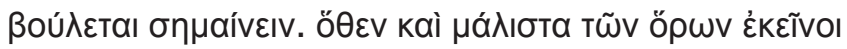

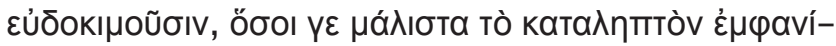

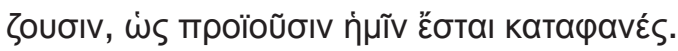

236.10

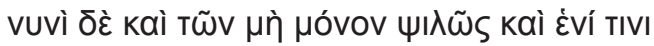

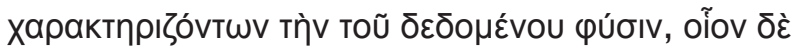

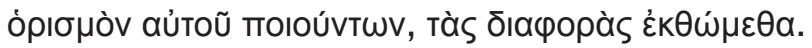

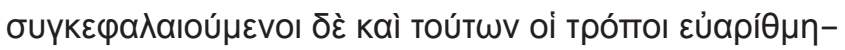

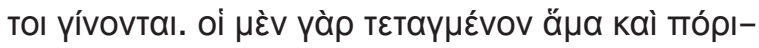

\subsection{5}

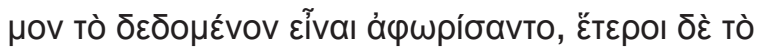

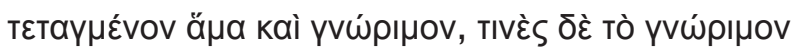

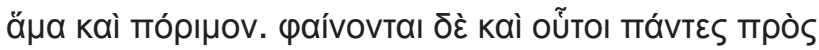

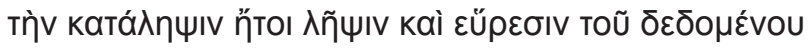

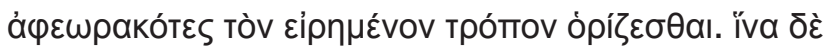


236.20

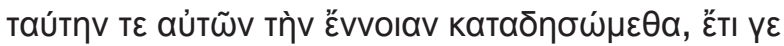

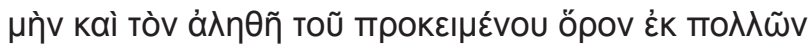

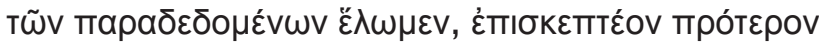

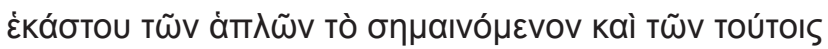

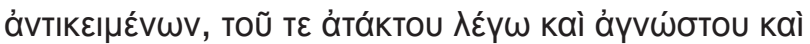

\subsection{5}

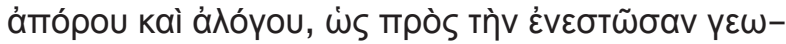

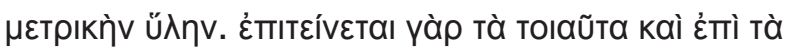

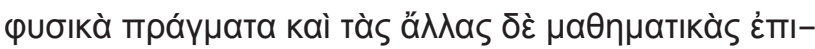
oтn்

\section{1}

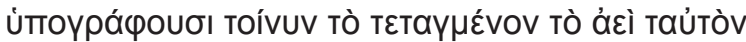

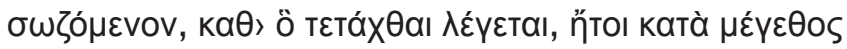

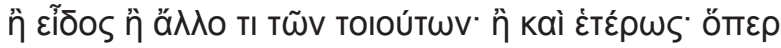

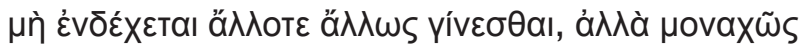

238.5

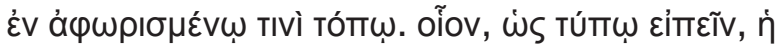

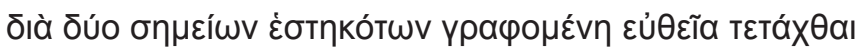

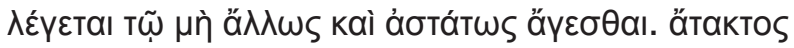

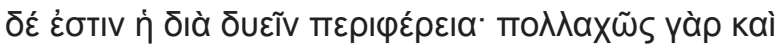

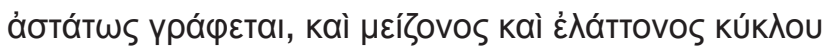

\subsection{0}

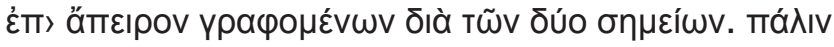

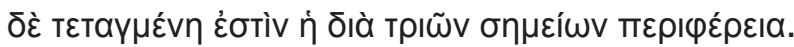

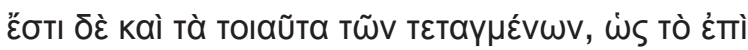

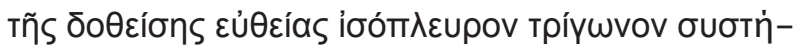

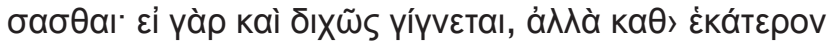




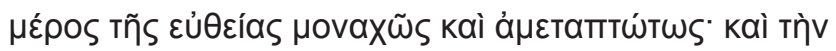

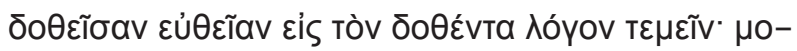

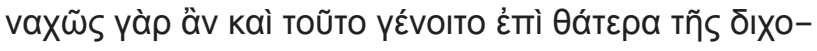

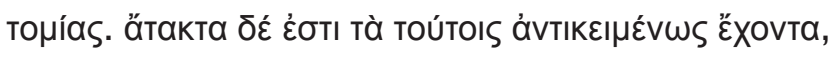

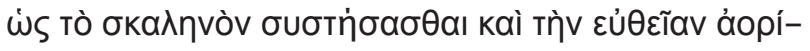

238.20

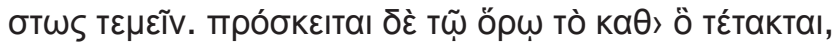

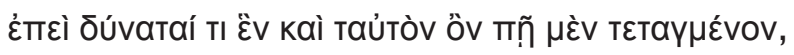

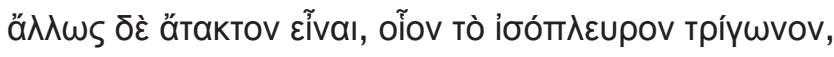

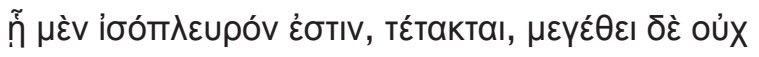
ய̈рıбтаı та̃v.

\subsection{5}

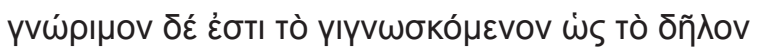

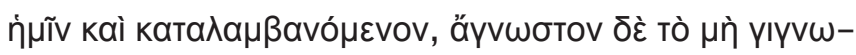

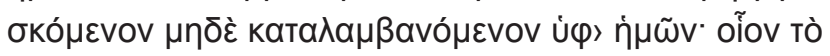

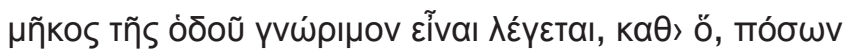

240.1

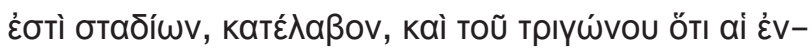

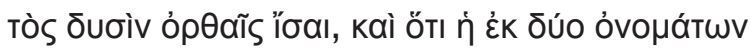

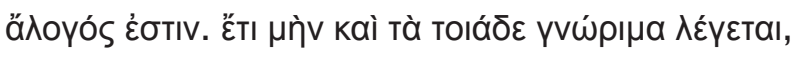

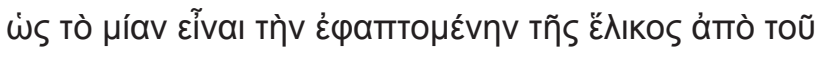

240.5

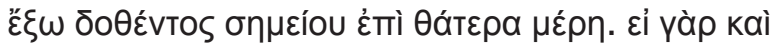

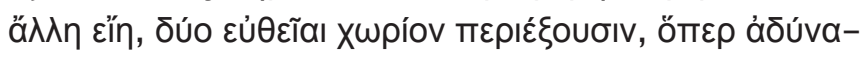

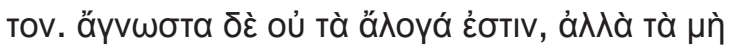

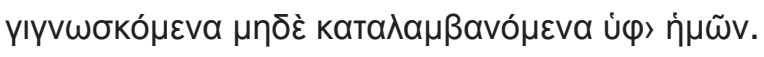

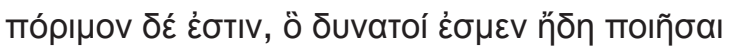


240.10

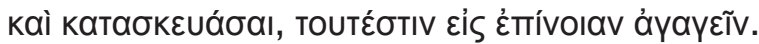

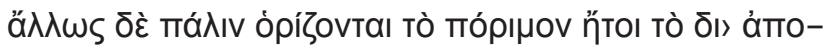

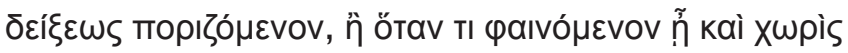

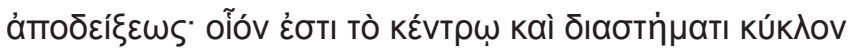

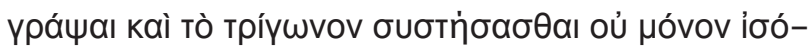

240.15

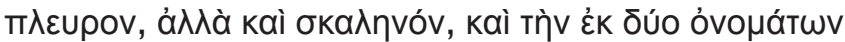

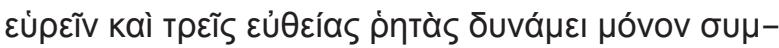

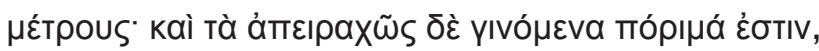

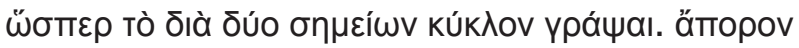

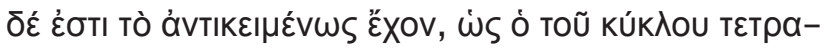

240.20

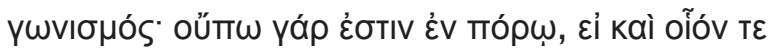

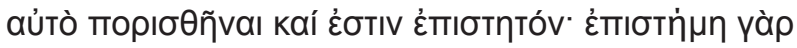

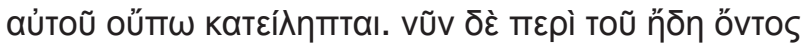

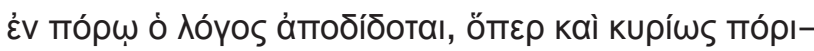

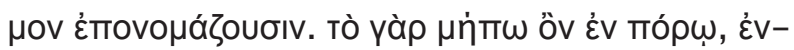

240.25

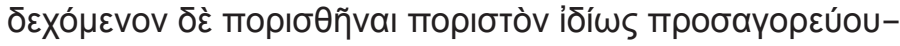

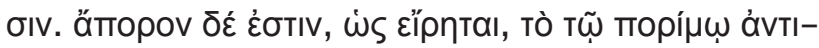

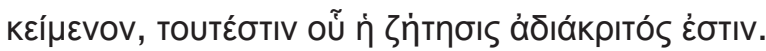

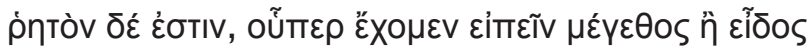

242.1

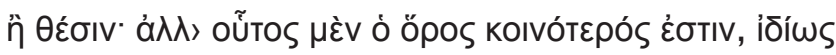

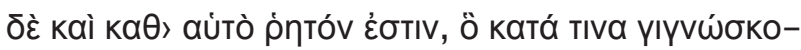

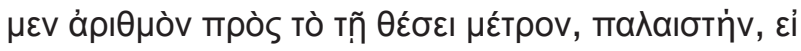

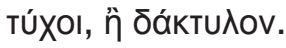




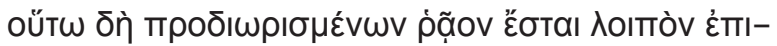

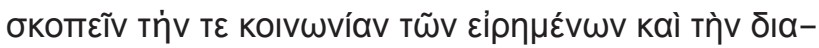

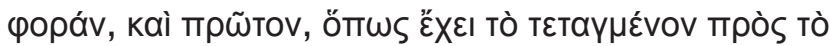

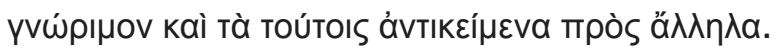

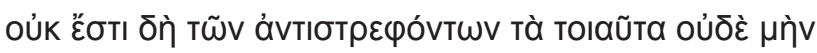

242.10

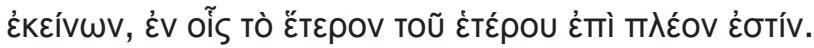

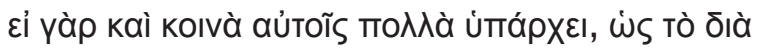

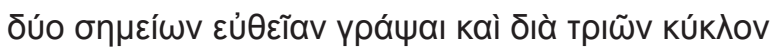

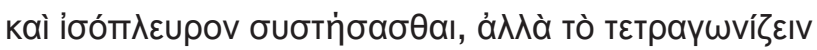

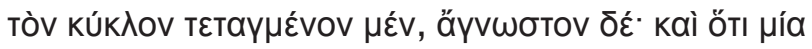

\subsection{5}

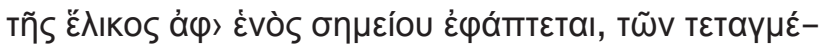

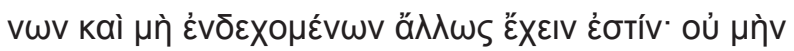

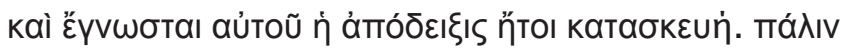

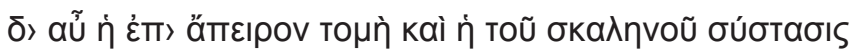

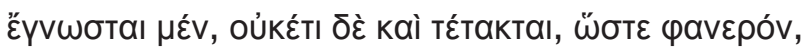

\subsection{0}

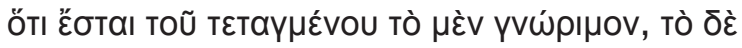

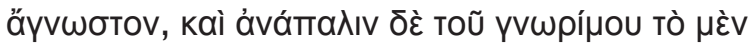

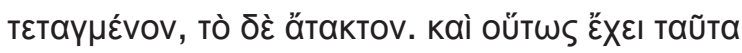
трò

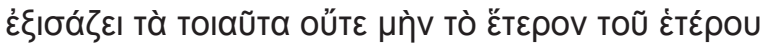

\subsection{5}

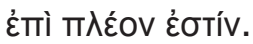

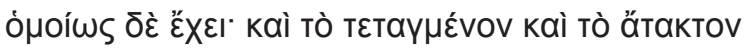

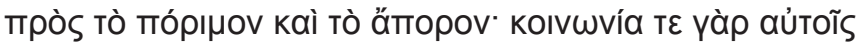

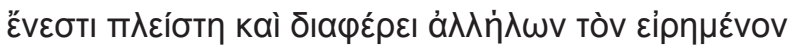


244.1

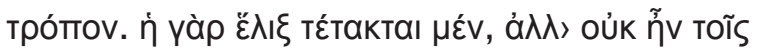

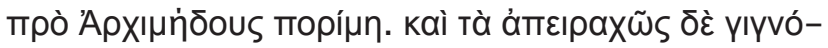

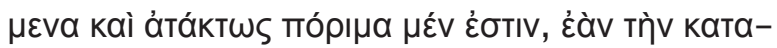

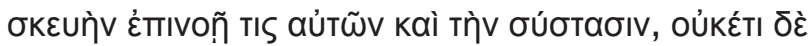

244.5

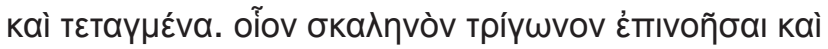

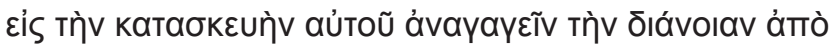

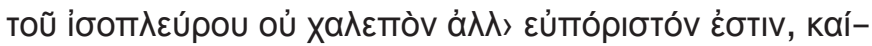

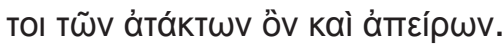

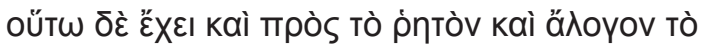

244.10

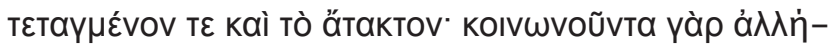

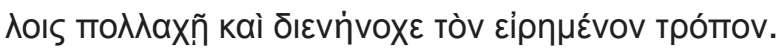

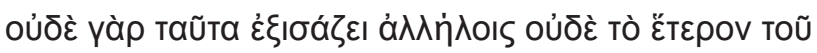

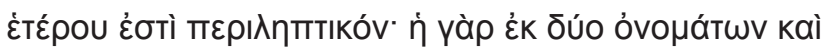

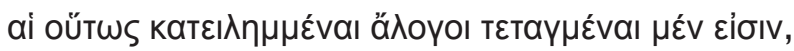

\subsection{5}

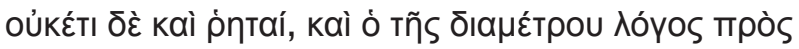

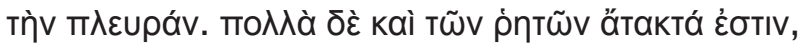

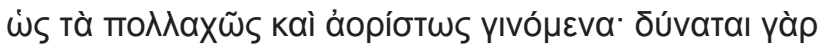

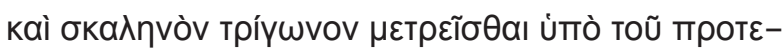

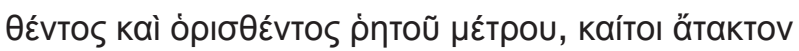

244.20

U்mápXov.

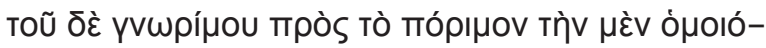

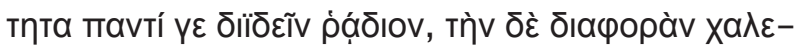

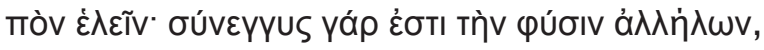

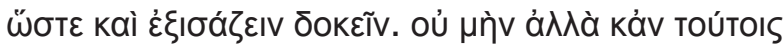




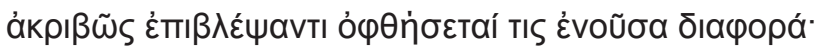

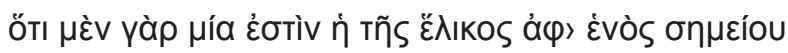

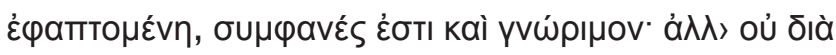

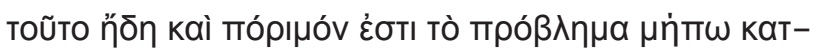

246.1

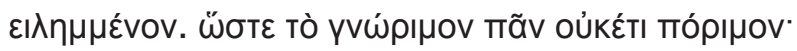

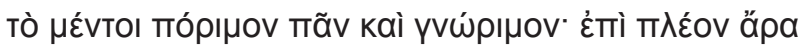

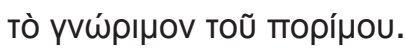

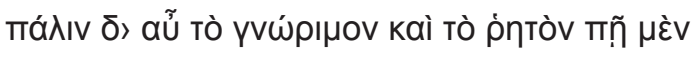

\section{5}

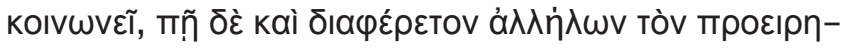

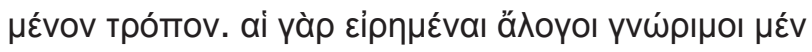

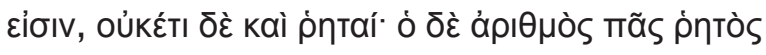

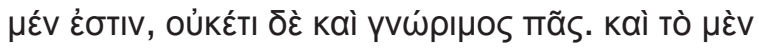

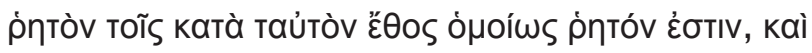

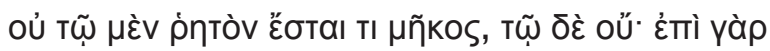

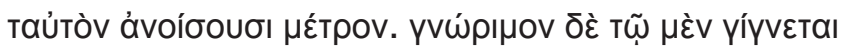

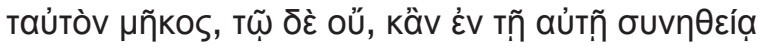

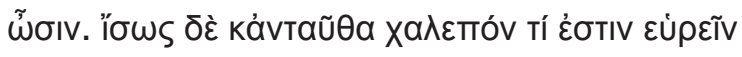

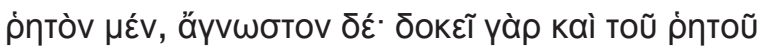

\subsection{5}

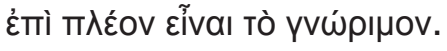

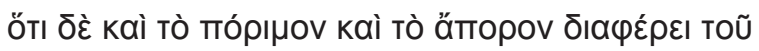

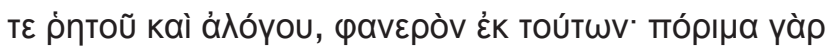

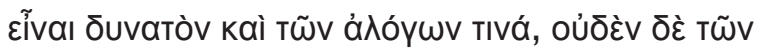

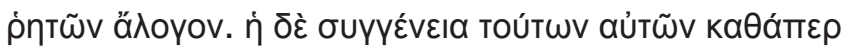


246.20

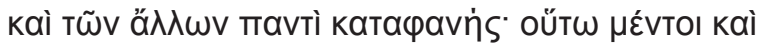

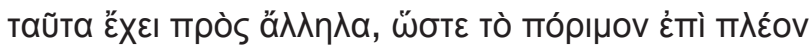

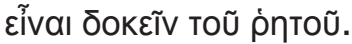

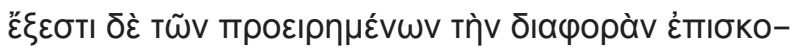

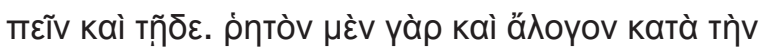

\subsection{5}

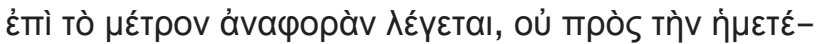

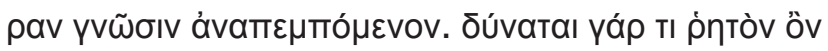

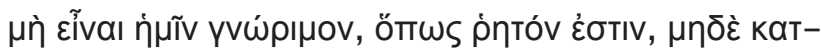

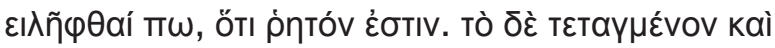

248.1

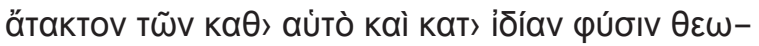

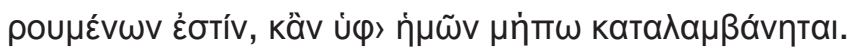

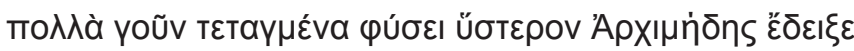

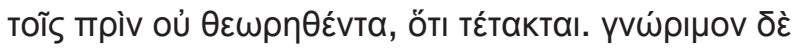

248.5

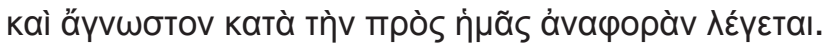

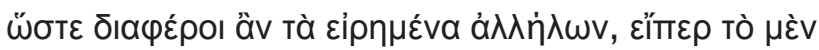

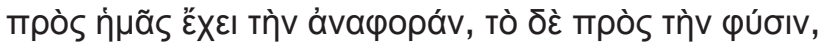

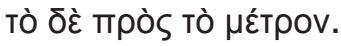

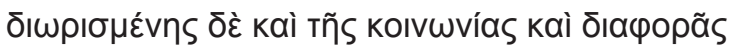

248.10

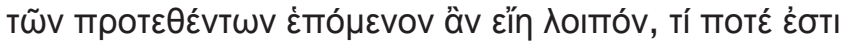

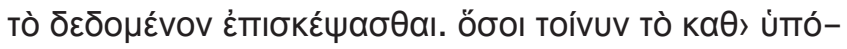

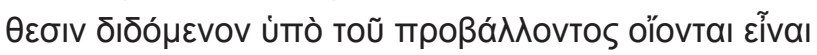

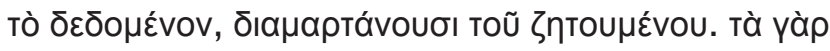

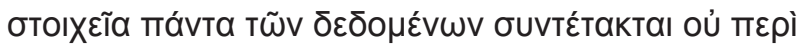




\subsection{5}

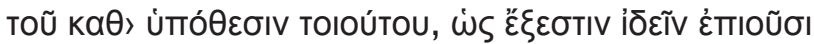

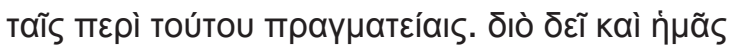

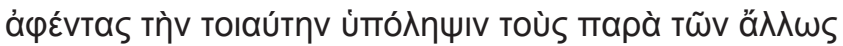

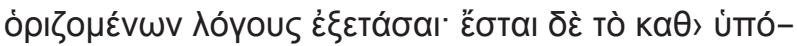

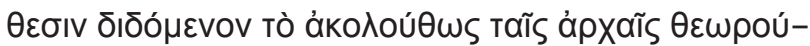

\subsection{0}

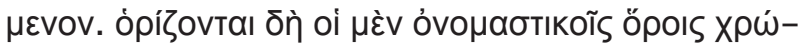

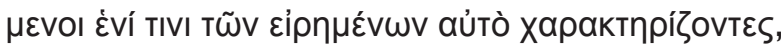

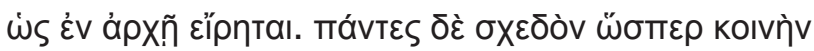

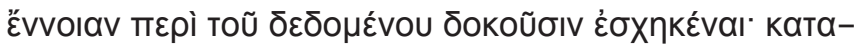

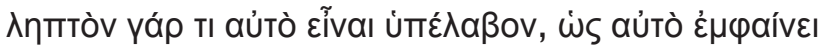

\subsection{5}

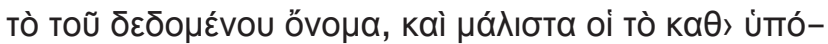
$\theta \varepsilon \sigma \mathrm{IV} \delta \varepsilon \delta$

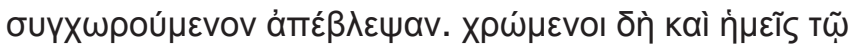

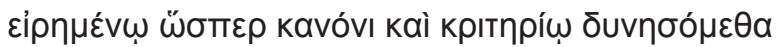

250.1

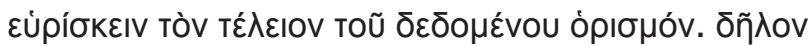

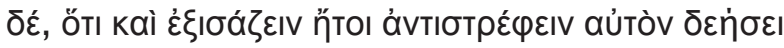

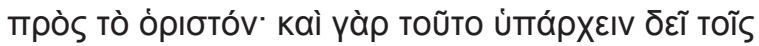

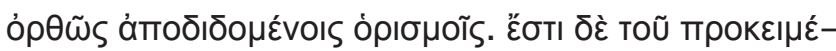

250.5

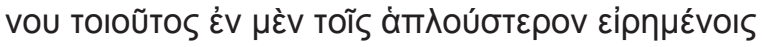

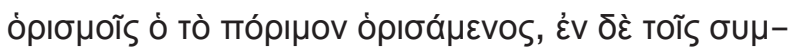

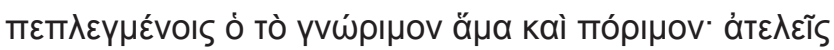

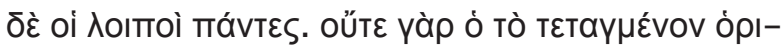

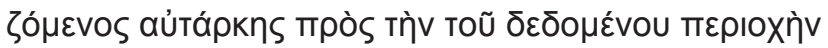


250.10

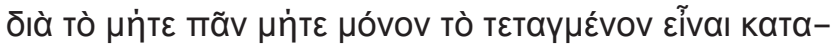

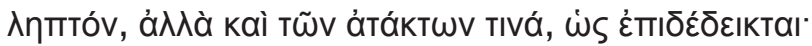

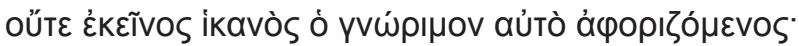

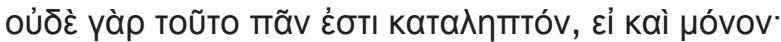

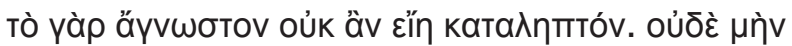

\subsection{5}

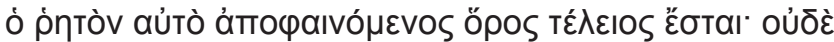

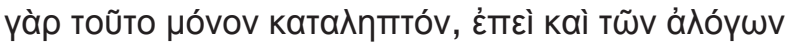

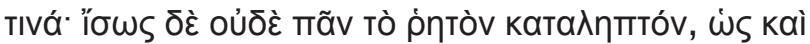

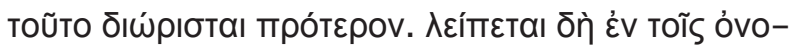

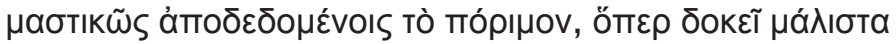

250.20

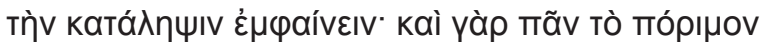

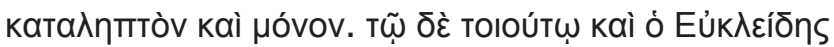

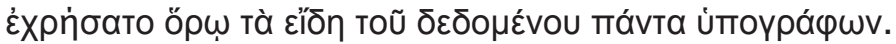

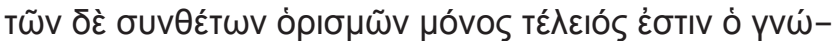

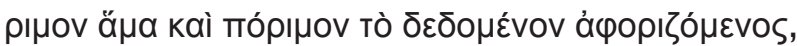

\subsection{5}

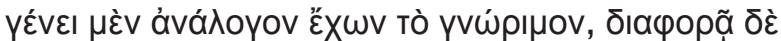

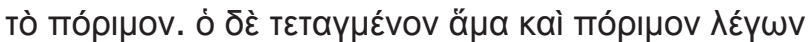

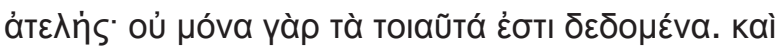

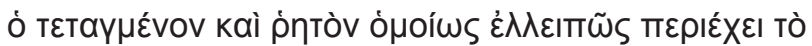

252.1

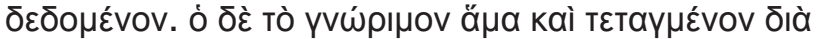

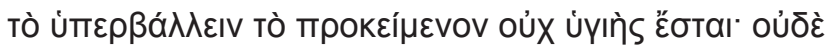

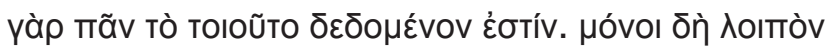

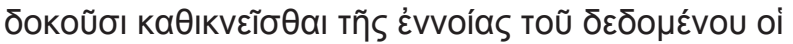




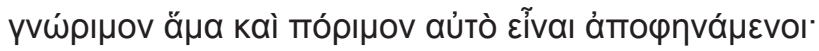

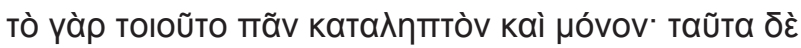

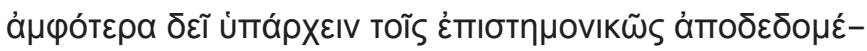

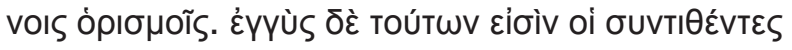

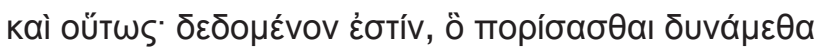

252.10

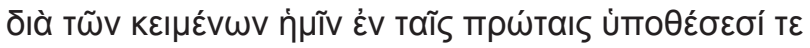

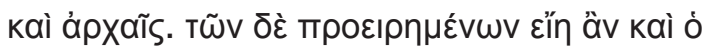

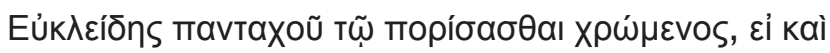

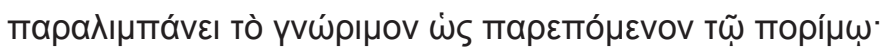

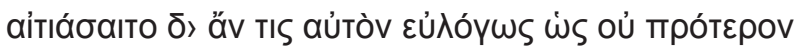

\subsection{5}

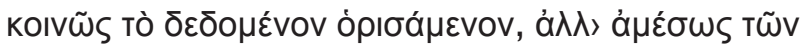

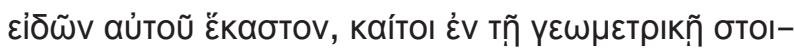

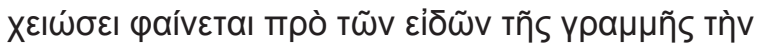

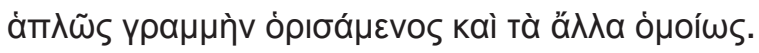

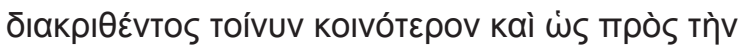

252.20

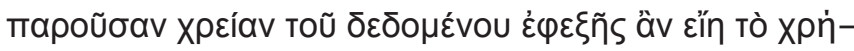

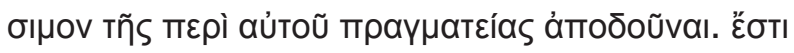

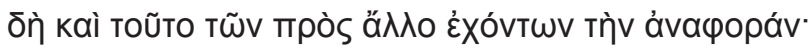

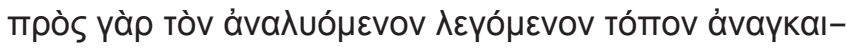

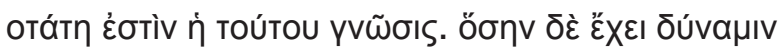

\subsection{5}

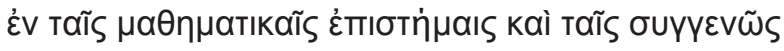

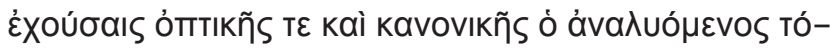

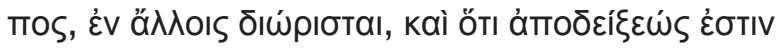


254.1

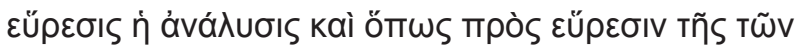

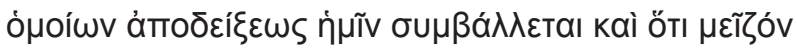

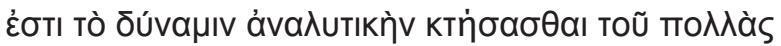

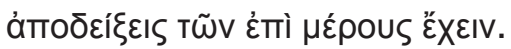

254.5

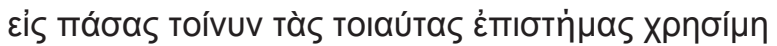

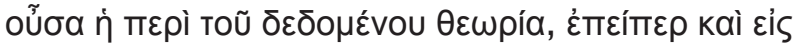

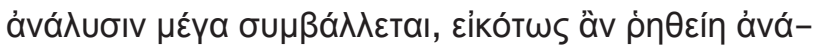

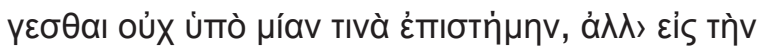

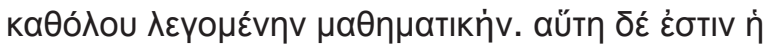

254.10

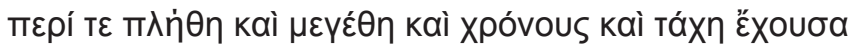

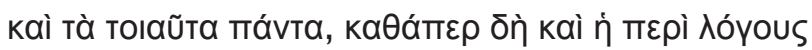

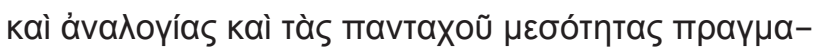

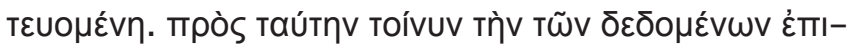

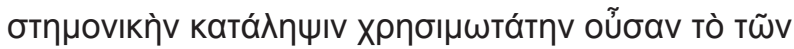

\subsection{5}

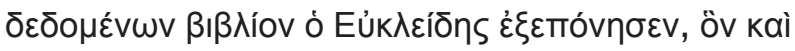

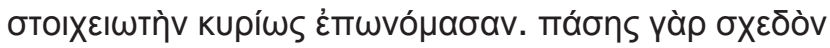

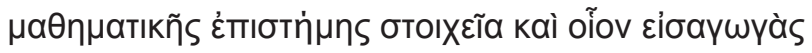

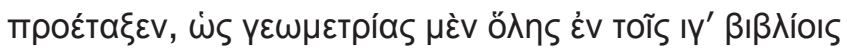

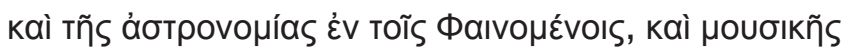

254.20

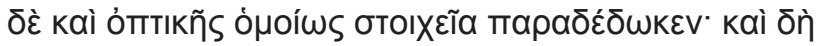

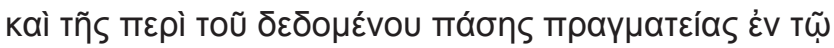

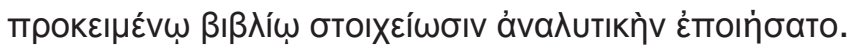

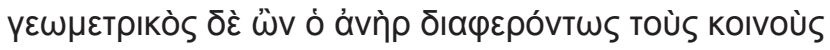

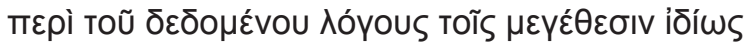




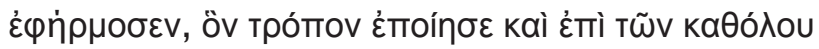

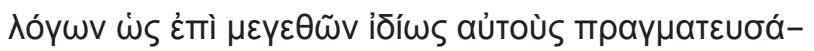

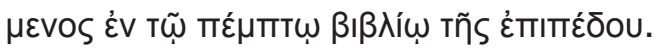

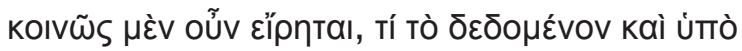

256.1

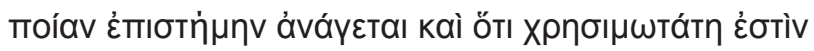

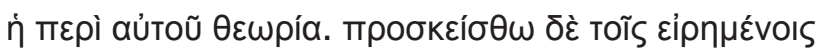

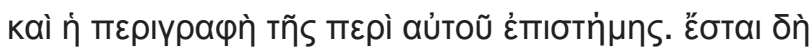

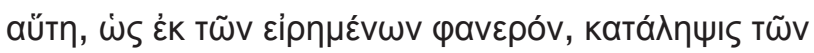

\section{5}

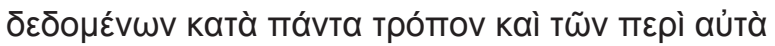

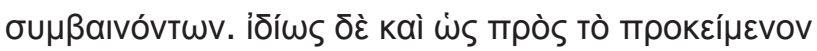

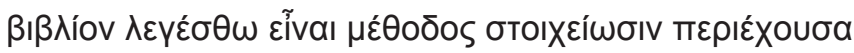

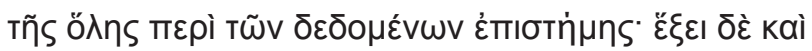

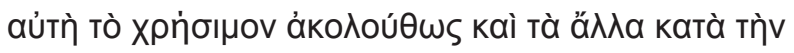

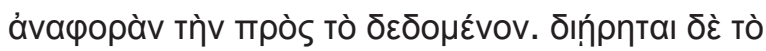

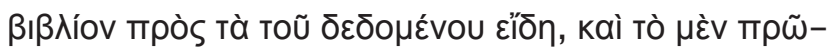

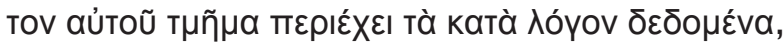

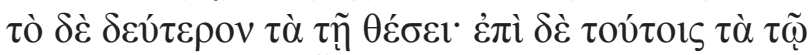

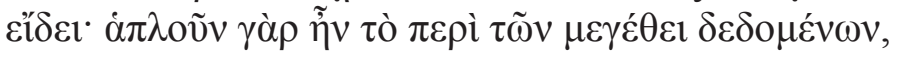

\subsection{5}

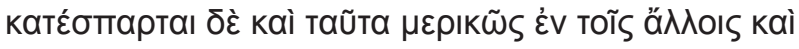

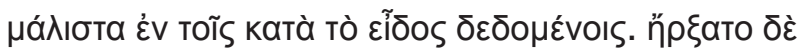

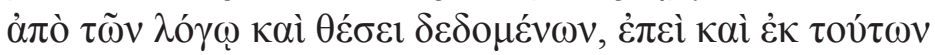

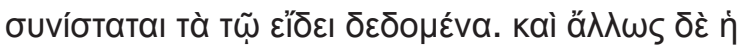

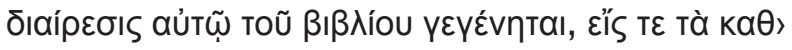


256.20

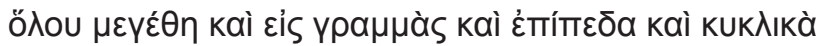

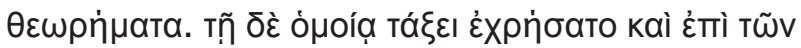

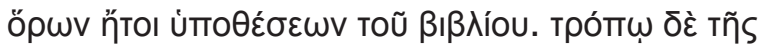

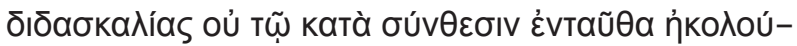

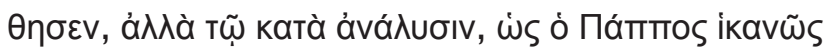

256.25

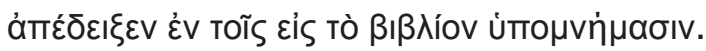

\section{Referências:}

Euclides. Data (grego-latim, com o comentário de Marino). Trad. Claude Hardy. Paris: M. Mondiere, 1625.

--- Data (grego-latim, com o comentário de Marino). Trad. H. Menge e I. L. Heiberg. Leipzig: Ed. Teubener, 1896 [Opera Omnia, v. VI].

--- Os elementos. Trad. Irineu Bicudo. São Paulo: Ed. Unesp, 2009.

Eves, Howard. Introdução à história da matemática.Trad. Higyno $\mathrm{H}$. Domingues. São Paulo: Ed. Unicamp, 2004.

Heath, Thomas L. A History of Greeks Mathematics. Nova York. Dover, 1981.

Michaux, Maurice (tradução e estudo crítico). Le commentaire de Marinus aux Data d'Euclide. Louvain: Bibliothèque de L'Université, 1947. 